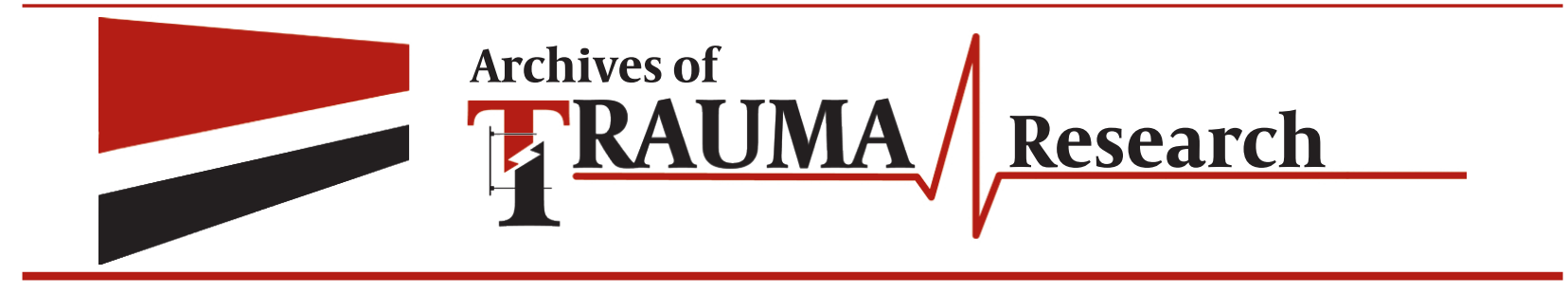

\title{
Pediatric Elbow Fractures in a Major Trauma Center in Iran
}

\author{
Akbar Behdad ${ }^{1}$, Samin Behdad ${ }^{2}$, Mehrdad Hosseinpour ${ }^{2, *}$ \\ ${ }^{1}$ Department of Surgery, Faculty of Medicine, Isfahan University of Medical Sciences, Isfahan, IR Iran \\ ${ }^{2}$ Trauma Research Center, Kashan University of Medical Sciences, Kashan, IR Iran \\ * Corresponding author: Mehrdad Hosseinpour, Trauma Research Center, Kashan University of Medical Sciences, Kashan, IR Iran. Tel.: +98-3112335547, Fax: \\ +98-3116262828, E-mail: meh_hosseinpour@yahoo.com.
}

\begin{abstract}
A B S T R A C T
Background: Elbow fractures are one of the most common traumatic fractures in the pediatric population. Since severe complications may occur, appropriate diagnosis and treatment are imperative when dealing with this type of fracture.

Objectives: The aim of this study was to evaluate the epidemiology of elbow fracture in children admitted in Alzahra hospital, Isfahan, IR Iran over a one year period.

Patients and Methods: During a one year period, a prospective study was conducted on 300 patients under the age of 16 who had sustained elbow fractures. Data included age, gender, mechanism of trauma, type of elbow fractures, complications, and outcomes.

Results: The mean age of the patients was $8.1 \pm 2.31$ years old. Boys were injured 2.6 times more often than the girls. Falling was the major cause of pediatric elbow fractures (86\%). Supra condylar were the most common type of fracture. There was a significant association between gender and type of injury $(\mathrm{P}<0.01)$.

Conclusions: Supracondylar fracture is the most common fracture type resulting from 4 - 8 year old boys' falls. Our findings indicate the critical nature of appropriate treatment in order to prevent severe complications.
\end{abstract}

Keywords: Elbow; Bone Fractures; Epidemiology; Pediatrics

Copyright @ 2013, Kashan University of Medical Sciences; Published by Kowsar

\section{Background}

Elbow fractures are among the most common traumatic problem in the pediatric population and consist of approximately $15 \%$ of the all pediatric fractures (1). In some studies, the cause of $85 \%$ of orthopedic surgeries is elbow fracture $(2,3)$. These fractures consist of supracondylar, lateral condyle, neck of radius, medial epicondyle, olecranon, head of radius and intercondylar fractures.
Supracondylar fracture is the most common fracture in children under seventeen years of age. Fracture of any extremity is rarely life-threatening, but it may cause major morbidity, inability to work, increased disability-adjusted life year (DALY) and severe psychological distress (4). Due to serious complications, timely diagnosis and treatment are considered as very important issue in this type

-Article type: Research Article; Received: 09 Sep 2012, Revised:14 Oct 2012, Accepted: 30 Oct 2012.

Implication for health policy/practice/research/medical education:

Elbow fractures are one of the most common traumatic fractures in the pediatric population. Since severe complications may occur, appropriate diagnosis and treatment are crucial in this type of fracture.

DPlease cite this paper as:

Behdad A, Behdad S, Hosseinpour M. Pediatric Elbow Fractures in a Major Trauma Center in Iran. Arch Trauma Res. 2012; 1(4):172-5. DOI: $10.5812 /$ atr.8098

Copyright (C) 2013, Kashan University of Medical Sciences; Published by Kowsar

This is an open-access article distributed under the terms of the Creative Commons Attribution License (http://creativecommons.org/licenses/by/3.0), which permits unrestricted use, distribution, and reproduction in any medium, provided the original work is properly cited. 
of fracture. The unique anatomy and the intimate location of neurovascular structures often result in a spectrum of injuries with associated complications (Cobitus varus, neurovascular injuries, and Volkman ischemic syndrome) and potential long-term disabilities $(5,6)$. The incidence of traumatic and iatrogenic nerve injuries with this type of fracture have been recorded as $12-20 \%$ and $2-6 \%$, respectively (7).

\section{Objectives}

The former Iranian studies conducted by Gorji (8) and Khaji (9) for the evaluation of epidemiology and mechanism of elbow fractures in children have limitations, and accurate data about the epidemiology of pediatric elbow fractures in Iran can only be achieved by the accumulation of data from all parts of the country. We conducted this study to assess the permutations of these injuries in children in one of the major trauma centers in Isfahan.

\section{Patients and Methods}

A descriptive case series study was carried out on 300 pediatric patients (all under sixteen years old) who were admitted to Alzahra educational hospital, Isfahan, Iran, from April 2011 to March 2012. Data about the patients and characteristics of their injuries were collected using patients' records. Radiographic studies (anterior-posterior and lateral view) were performed in order to confirm the elbow fracture and following verification from the specialist, patients were admitted for a final evaluation. Etiology of injury, demographic data (age, gender), type of fractures and left or right arm dominancy were collected. Collected data were classified and reported in distribution of frequency tables. For evaluation, the relationship between type of fracture, age, gender and injured hand, Chi -Square or Exact Fissure's test was utilized. Results were considered significant at $\mathrm{P} \leq 0.05$.

\section{Results}

of the 300 patients admitted to hospital due to an accident, 217 cases (72.3\%) were male and 83 (27.7\%) female. The mean age of patients was $8.1 \pm 2.31$ years. Table 1 illustrated the frequency of distribution according to age. According to this table, the age group of the patients was 4 - 8 years. Table 2 illustrated the distribution of the type of fracture.

\begin{tabular}{ll}
\hline \multicolumn{2}{l}{ Table 1. Distribution of Elbow Fracture According to Age Group } \\
\hline Age Group, $\mathbf{y}$ & No. $(\%)$ \\
\hline $\mathbf{0}$ - $\mathbf{4}$ & $58(19.3)$ \\
$\mathbf{4}-\mathbf{8}$ & $113(37.7)$ \\
$\mathbf{8}$ - $\mathbf{1 2}$ & $76(25.3)$ \\
$\mathbf{1 2}-\mathbf{1 6}$ & $53(17.7)$ \\
\hline
\end{tabular}

Table 2. Distribution of Elbow Fracture According to Type of Fracture

\begin{tabular}{|ll}
\hline Type of Fracture & No. $(\%)$ \\
\hline Supra condylar & $174(58.0)$ \\
\hline Lateral condyl & $28(9.3)$ \\
\hline Neck of radius & $22(7.3)$ \\
\hline Medial epicondyl & $13(4.3)$ \\
\hline Olecranone & $16(5.3)$ \\
\hline Head of radius & $32(10.7)$ \\
\hline Inter condylar & $9(3.0)$ \\
\hline Mix & $6(2.0)$ \\
\hline
\end{tabular}

According to this table, supracondylar fracture is the most common type in patients under sixteen years. Accidental falls accounted for $86 \%$ of supracondylar fractures. Other etiologies were traffic accidents (13.2\%) and violence ( $8 \%)$. One hundred and seventy six patients (58.7\%) have left elbow fracture and 124 of them (41.3\%) suffered a right elbow fracture. Table 3 illustrated the frequency distribution of the type of fractures according to the age groups. As stated in this table, supracondylar fractures are more common in 4-8 years old children ( $P$ $=0.05$ ). Furthermore, Table 4 illustrated the frequency distribution of the type of injury according to gender. Elbow fractures were more common in the male gender $(\mathrm{P}=0.01)$. There were no significant differences between the dominancy of arm and fracture types (Table 5). The types of supracondylar fractures were not mentioned in patients' records.

\section{Discussion}

In this study, supracondylar fracture was presented in $58 \%$ of all cases and was the most common cause of elbow fracture in patients under 16 years of age, a finding that was similar to the Jessica study (10).

Table 3. Frequency of Type of Elbow Fracture According to Age Group

\begin{tabular}{llllll}
\hline Age Group, & $\begin{array}{l}\text { Supra Condylar, } \\
\text { No. }\end{array}$ & $\begin{array}{l}\text { Head of Radius, } \\
\text { No. }\end{array}$ & $\begin{array}{l}\text { Lateral Condyle, } \\
\text { No. }\end{array}$ & $\begin{array}{l}\text { Neck of Radius, } \\
\text { No. }\end{array}$ & $\begin{array}{l}\text { Olecranon, No. } \\
\text { 0-4 }\end{array}$ \\
\hline $\mathbf{4}$ - 8 & 75 & 9 & 4 & 4 & 4 \\
\hline $\mathbf{8 - 1 2}$ & 47 & 11 & 15 & 7 & 5 \\
$\mathbf{1 2}$ - $\mathbf{1 6}$ & 22 & 6 & 6 & 7 & 2 \\
\hline
\end{tabular}




\begin{tabular}{lll}
\hline \multicolumn{2}{l}{ Table 4. Frequency of Type of Fracture According to Gender } \\
\hline Type of Fracture & Male, No. & Female, No. \\
\hline Supra condylar & 125 & 49 \\
\hline Head of radius & 17 & 15 \\
\hline Neck of radius & 16 & 6 \\
\hline Lateral condyle & 21 & 7 \\
\hline Olecranon & 13 & 3 \\
\hline
\end{tabular}

Table 5. Frequency of Elbow Fracture According to Side of Injury

\begin{tabular}{lll}
\hline Type of Fracture & Right, No. & Left, No. \\
\hline Supra condylar & 68 & 106 \\
\hline Head of radius & 13 & 19 \\
\hline Lateral condyle & 13 & 15 \\
\hline Neck of radius & 9 & 13 \\
\hline Olecranon & 6 & 10 \\
\hline
\end{tabular}

The injury was on the outstretched arm which resulted in hyperextension of the elbow and was caused by falling from a height. Falls and traffic crashes were the main causes of injuries, with the percentages of $86 \%$ and 13.2\% that in Khaji study were $57.3 \%$ and $37.1 \%$, respectively (9). Association between age groups and supracondylar fracture was repeated in other studies. The incidence of this type of fracture peaks between $2-7$ years (11). This peak is thought to be associated with the fact that the capsule and ligaments supporting the elbow have been revealed to have greater tensile strength than the bone itself, which leads to preferential fracture of the vulnerable supracondylar region when sufficient force is applied across it. Seventy-five percent of supracondylar fracture occurred in males, which correlates to the Marquis study (11). Uncontrolled and unlimited playing for boys such as cycling and playground injuries make the male gender more vulnerable to fracture (12). In our study, there was no significant relation between dominant elbow and fracture but most of them were in the left elbow as stated by Igbigbi (13). In Chai and Chakraborty studies, the non-dominant arm was more frequently affected than the dominant $\operatorname{arm}(14,15)$. There is no definitive etiology for the more common left elbow fracture but the explanation is that most patients were right dominant and since the left arm is weaker than the other arm, the force of the fall caused the fracture in the weaker elbow. In the present study, fracture of the head of the radius was common following the supracondylar fracture which is the inverse of Biruk's study. In his study, the next common type was a medial condylar fracture (16) as well as in Lipczyk's study, the lateral humeral condyle was the second most common elbow fracture in children after supracondylar fracture of the humerus (17). Finally, a recent study showed that supracondylar fractures are the most common particularly in boys aged $4-8$ years after falling. To avoid severe complications, an accurate diagnosis and in time treatment is crucial. The present study has the usual limitations of being a retrospective study when it comes to collection of data about the fractures and early complications.

\section{Acknowledgments}

We thank Mrs. Mohadese Hamsaie for her contribution in data collection.

\section{Authors' Contribution}

Dr. Akbar Behdad: study management, Dr. Samin Behdad: data collection and analysis and involved in writing the manuscript, Dr. Mehrdad Hosseinpour: study design.

\section{Financial Disclosure}

There is no financial disclosure.

\section{Funding/Support}

There is no financial support.

\section{References}

1. Shrader MW. Pediatric supracondylar fractures and pediatric physeal elbow fractures. Orthop Clin North Am.2008;39(2):163-71.

2. Manning Ryan L. Evaluation and Management of Supracondylar Fractures in Children. Hand Clin.2006;22(1):77.

3. Hart ES, Turner A, Albright M, Grottkau BE. Common pediatric elbow fractures. Orthop Nurs.2011;30(1):11-7.

4. Polinder S, Meerding WJ, Mulder S, Petridou E, van Beeck E. Assessing the burden of injury in six European countries. Bull World Health Organ.2007;85(1):27-34.

5. Chai KK, Aik S, Sengupta S. Supracondylar fractures of the humerus in children-an epidemiological study of 132 consecutive cases. Med J Malaysia.2000;55:39-43.

6. Milbrandt TA, Copley LAB. Common elbow injuries in children evaluation, treatment, and clinical outcomes. Curr Opin Orthop.2004;15(4):286-94.

7. Ramachandran M, Birch R, Eastwood DM. Clinical outcome of nerve injuries associated with supracondylar fractures of the humerus in children: the experience of a specialist referral centre. $J$ Bone Joint Surg Br.2006;88(1):90-4.

8. Gorgi J, Panjavi B, Abbaszadeh MR. Lateral Humeral Condyle Fracture in Children. Iran J Orthop Surg.2007;6:7.

9. Khaji A,Zargar M, Karbakhsh M. Extremity fractures in children:a hospital based study in Tehran. Chin J Traumatol.2010;13(4):217-21.

10. Jessica C, Babal BS, Chales T. Nerve Injuries Associated With Pediatric Supracondylar Humeral fracture :A Meta -analysis. J Pediatr Orthop.2010;30:253-3.

11. Marquis CP, Cheung G, Dwyer JSM, Emery DFG. Supracondylar Fractures Of TheHumerus. Cur Orthopaed.2008;22(1):62-9.

12. Howard AW, Macarthur C, Rothman L, Willan A, Macpherson AK School playground surfacing and arm fractures in children: a cluster randomized trial comparing sand to wood chip surfaces. PLoS Med.2009;6(12): e1000195.

13. Igbigbi PS, Manda K. Epidemiology of humeral fractures in Malawi. Int Orthop.2004;28(6):338-41

14. Babar IU, Shinwari N, Bangash MR, Khan MS. Management of supracondylar fracture of humerus in children by close reduction 
and immobilization of the elbow in extension and supination. $J$ Ayub Med Coll Abbottabad.2009;21(4):159-61.

15. Chakraborty MK, Onta PR, Sathian B. Displaced supracondylar fracture of humerus in children treated with crossed pin versus lateral pin: A hospital based study from Western Nepal. Journal of Clinical and Diagnostic Research. West Nepal J of Clinic Diagn
Res.2011;5(6):1260-3.

16. Biruk LW, Admassie D, Banchiamlak A. Fractures Around Child's Elbow-Radiological Patterns. East Cent Afric J Surg.2008;13(2).

17. Lipczyk Z, Flont P, Golanski G, Niedzielski KR. [Analysis of treatment results of humeral lateral condyle fractures in children]. Chir Narzadow Ruchu Ortop Pol.2011;76(6):327-31. 